\title{
Prevalence of Missed Nursing Care and Associated Factors - a Nurse's Perspective - at the Oncology Departments in Gaza Strip, Palestine
}

\begin{abstract}
Albelbeisi $\mathrm{AH}^{1 *}$, Shaqfa $\mathrm{KM}^{2}$, Aiash $\mathrm{HS}^{3}$, Kishta $\mathrm{WA}^{4}$ and Alreqeb EI ${ }^{4}$

${ }^{1}$ Nursing Research Committee, General Directorate of Nursing, Palestinian Ministry of Health, Gaza Strip Palestine

${ }^{2}$ General Directorate of Nursing, Palestinian Ministry of Health, Gaza Strip, Palestine

3Planning and Quality Control Unit, Palestinian Ministry of Health, Gaza Strip, Palestine

${ }^{4}$ Nursing Research Committee, European Gaza Hospital, Palestinian Ministry of Health, Gaza Strip, Palestine

*Corresponding author: Ali H. Albelbeisi, Nursing Research Committee, General Directorate of Nursing, Palestinian Ministry of Health, Gaza Strip, Palestine
\end{abstract}

Received: August 28, 2021; Accepted: September 22, 2021; Published: September 29, 2021

\begin{abstract}
Background: The present study aims to determine the prevalence of nursing missed care and associated factors at the oncology departments in Gaza Strip, Palestine.

Method: This cross sectional study was conducted among all nurses who worked at the only two hospitals offer oncology nursing care in Gaza Strip, Palestine between May to July 2020 using a self-administered questionnaire.

Results: Data from 52 nurses (44 had bachelor and 8 had diploma certificate) on five oncology departments in the European Gaza and Al-Rantisi hospitals revealed that the overall prevalence of missed nursing care was $39 \%$. The most common areas of missed care reported were; providing oral hygiene for those who need $(n=39,75 \%)$, treatments and some of nursing procedures left undone because of lack of time $(n=34,65.3 \%)$, and always nurses consider cleaning of patient's room or equipment $(n=30,57.7 \%)$. The main factors leading to missed nursing care were lack of enough nurses, no opportunity for nurses to participate in policy decisions, absent of active quality assurance program, management do not listen and response to employee concerns, and there is no a preceptor program for newly hired nurses (weighted means: $37.8 \%, 37.4 \%$, $36.8 \%, 36 \%$, and $35 \%$, respectively).
\end{abstract}

Conclusion: The findings of the present study demonstrated the need for more quality improvement efforts to reduce missed nursing care in the oncology departments. Considering issues such as shortage in staff number, nurses' continuing education/training programs and involvement in policy decisions, and direct response to the career concerns could reduce the prevalence of missed care.

Keywords: Nursing; Missed nursing care; Oncology departments; Nurses

\section{Introduction}

Missed nursing care, for the purpose of this study, is defined as "any aspect of required patient care that is omitted (either in part or in whole) or delayed" [1]. Cancer nurses play a critical role in the delivery of care to patients in oncology inpatient settings. Cancer nursing requires skill and attention to physical, emotional and spiritual aspects of care for patients [2,3] and includes knowledge and preparation to deliver complex, multimodality therapies and initiate timely management of their side-effects to ensure the best outcomes for patients [4].

Missed nursing care has unequivocally and repeatedly been associated with poorer patient outcomes, increased length of hospital stay, and a decrease in patient reported satisfaction with their hospital care experience [5]. Nurses' job satisfaction, intent to stay in their career, burnout, and the quality with which they rate their personal life have all been demonstrated to be impacted by not being able to give the quality of care that they believe their patients demand $[6,7]$. Missed nursing care has been shown to be influenced by many complex factors. Hospital resources, the working environment of the ward, nurse patient ratios, and the number of hours a nurse works per shift have all been associated with missed nursing care [8-10].

The body of literature related to unfinished and missed nursing care has grown significantly over the last decade and a cursory review suggests that unfinished care is a global problem [11]. In preparation for this study, to the best of our knowledge, no previous studies addressed missed nursing care in oncology settings were found. As such an understanding of missed nursing care in inpatient oncology settings in Palestine is limited. Therefore, the purposes of this study were to explore and describe missed nursing care in the oncology departments in Gaza Strip, and factors perceived by nurses to result in missed care.

\section{Methods}

\section{Sampling and data collection}

This cross sectional study was conducted among nurses who worked at the only two hospitals offer oncology nursing care in Gaza Strip between May to July 2020. Study participants were selected using census sampling from nurses working in male, female, and pediatric oncology wards at the European Gaza Hospital and Al- 
Rantisi Hospitals these being seen as representative of general inpatient wards in Gaza Strip, Palestine.

Having obtained approval from the General Directorate for Manpower Development of Palestinian Ministry of Health. Nurses working the morning, evening, and night shifts on the selected wards and who met the inclusion criteria (i.e. having at least one year of work experience in the selected wards, working full time and willing to participate) were identified by the research assistants (two registered nurses) who distributed the survey questionnaire and information about the present study. In total 52 questionnaire were circulated by the research assistants. Participants were asked to complete and return the questionnaire within two working days.

\section{Data collection too}

Data was gathered using the nursing missed care questionnaire developed by the researcher after checking of its validity and reliability using a pilot study. This questionnaire consisted of three parts; part one consisted of 15 items in which the participants were asked to determine the staffing levels and workload including questions about the total number of patients in the last shift, total number of registered nurse, and number of patients were required hourly nursing care. Part two included 27 items in which the participants were required to indicate the nursing missed care associated factors using a 5-point Likert scale with score ranging from 1 to 5 ( $1=$ strongly disagree, 2 $=$ disagree, $3=$ neutral, $4=$ agree, and $5=$ strongly agree). Part three included 15 items in which participants were asked to indicate the nursing missed care during the last working shift using a 3-point Likert scale with scores ranging from 1 to 3 (where $1=$ yes (means not missed), 2 = sometimes, and 3 = never).

\section{Statistical analysis}

SPSS for Windows, version 25, was used for data analysis. Descriptive statistics were used to describe continuous and categorical data. The prevalence of the nursing missed care and associated factors were determined by calculation of the weighted mean (The weighted mean involved multiplying each data point in a set by a value which is determined by some characteristic of whatever contributed to the data point).

\section{Ethical considerations}

Ethical clearance was obtained from the Helsinki Ethics Committee of Gaza Strip. Further, approval from the General Directorate for Manpower Development of Palestinian Ministry of Health was obtained. Written informed consent was obtained from all participants through the use of a form signed by them and which advised them that they could withdraw from the study at any stage. Confidentiality and anonymity was maintained for all information collected during the study.

\section{Results}

Table 1 shows the socio-demographic characteristics of the participants. Fifty two nursing staff participated in this study, $42.3 \%$ of which were male and $57.7 \%$ were female with mean age $33.96 \pm 8.26$ years. About $59.6 \%$ of the participants were from $\mathrm{Al}$ Rantisi hospital and $40.4 \%$ from the European Gaza Hospital (EGH) and approximately $84.6 \%$ of them had bachelor degree or more. Participants' mean work experience was $10.50 \pm 6.40$ years.
Table 1: Socio-demographic characteristics of the study participants $(n=52)$.

\begin{tabular}{|c|c|c|}
\hline Variable & $\begin{array}{l}\text { No. of } \\
\text { respondent (\%) }\end{array}$ & Mean \pm SD \\
\hline \multicolumn{3}{|l|}{ Hospital } \\
\hline EGH & $21(40.4)$ & \\
\hline Rantisi & $31(59.6)$ & \\
\hline \multicolumn{3}{|l|}{ Department } \\
\hline Adult male & $18(34.6)$ & \\
\hline Adult female & $23(44.2)$ & \\
\hline Pediatric & $11(21.2)$ & \\
\hline Age (Year) & & $33.96 \pm 8.26$ \\
\hline $24-33.9$ & $29(55.8)$ & \\
\hline $34-43.9$ & $17(32.7)$ & \\
\hline $44-53.9$ & $3(5.8)$ & \\
\hline$\geq 54$ & $3(5.8)$ & \\
\hline \multicolumn{3}{|l|}{ Gender } \\
\hline Male & $22(42.3)$ & \\
\hline Female & $30(57.7)$ & \\
\hline \multicolumn{3}{|l|}{ Job title } \\
\hline Staff member & $45(86.5)$ & \\
\hline Senior Nurse & $2(3.8)$ & \\
\hline Head nurse & $5(9.6)$ & \\
\hline \multicolumn{3}{|l|}{ Educational level } \\
\hline Diploma & $8(15.4)$ & \\
\hline Bachelor & $40(76.9)$ & \\
\hline Master or more & $4(7.7)$ & \\
\hline Years of experience (Year) & & $10.50 \pm 6.40$ \\
\hline $\begin{array}{l}\text { Length of service in current hospital } \\
\text { (Year) }\end{array}$ & & $7.70 \pm 5.53$ \\
\hline \multicolumn{3}{|l|}{ Last shift } \\
\hline Day & $35(67.3)$ & \\
\hline Evening & $4(7.7)$ & \\
\hline Night & $9(17.3)$ & \\
\hline Evening-Night & $4(7.7)$ & \\
\hline Salary (NIS) ${ }^{1}$ & & $1401.86 \pm 429.79$ \\
\hline
\end{tabular}

${ }^{1} \mathrm{New}$ Israeli Shekel

\section{Staffing levels and workload}

As shown in Table 2, the mean number of patients were in ward in the last shift and mean of the total number of registered nurses in ward (divided into three shifts) were $11.01 \pm 3.41$ patients and $8.05 \pm 3.53$ nurses, respectively. Further, mean number of patients were his/her responsibilities in last shift was $6.11 \pm 2.47$ patients. Approximately $55.8 \%$ of participants reported that they provided most of nursing care by theirself. The mean number of hours the nurses did work in last shift was $8.30 \pm 3.36$ hours.

\section{Prevalence of nursing missed care}

As shown in Table 3, the total prevalence of missed care (completely and partially not performed) was 39\%. Approximately $75 \%$ of the respondents reported that they had missed oral hygiene for patients who need. About $65.3 \%$ and $57.7 \%$ of participants 
Table 2: Staffing levels and workload.

\begin{tabular}{|c|c|c|}
\hline Variable & n (\%) & Mean $\pm S D$ \\
\hline Number of patients were in your ward in the last shift & & $11.01 \pm 3.41$ \\
\hline $\begin{array}{l}\text { Number of registered nurse (Bachelor and above) is in } \\
\text { your ward }\end{array}$ & & $8.05 \pm 3.53$ \\
\hline Number of patients were your responsibility in last shift & & $6.11 \pm 2.47$ \\
\hline Number of patients were required hourly nursing care & & $4.69 \pm 2.81$ \\
\hline \multicolumn{3}{|l|}{ Describe your last shift } \\
\hline I provided most of the care myself & $29(55.8)$ & \\
\hline $\begin{array}{l}\text { I supervised the care by others and provided some } \\
\text { myself }\end{array}$ & $17(32.7)$ & \\
\hline $\begin{array}{l}\text { I provided limited care and most care was provided by } \\
\text { others }\end{array}$ & $6(11.5)$ & \\
\hline Number of hours did you work in last shift & & $8.30 \pm 3.36$ \\
\hline
\end{tabular}

showed that treatments and some of nursing procedures left undone because of lack of time and always they don't consider cleaning of patients' rooms and equipment, respectively. Whereas, only $21 \%$ of the participants demonstrated that they don't comfort/talk with patients or provide adequate document nursing care. Figure 1 shows the prevalence of nursing missed care based on those who answered no.

\section{Nursing missed care associated factors perceived by nurses}

As presented in Table 4, approximately $63.5 \%$ of the participants showed that there are no enough registered nurse on staff to provide quality patient care (weighted mean $=37.8 \%$ ). Moreover, about $57 \%$ and $61.5 \%$ of the participants demonstrated that there is no opportunity for the registered nurse to participate in policy decision and there is no enough staff to get the work done, respectively
( weighted mean $=37.4 \%$ and $36.8 \%$, respectively). Around half $(52 \%$ and $46 \%$, respectively) of participants showed that there is no active quality assurance program as well as management do not listen and respond to employee concerns (weighted mean $=36 \%$ and $35 \%$, respectively).

In contrast, only $11.5 \%$ of the participants presented that the actions of hospital management do not show that patient safety is a top priority (weighted mean $=23.6 \%$ ). Also, $7.7 \%$ of them reported that doctors and nurses do not have good working relationship (weighted mean $=24.6 \%$ ), and $10 \%$ of the participants reported that they do not discuss ways to prevent errors from happening again ( weighted mean $=24.8 \%$ ).

\section{Discussion}

In the current study $39 \%$ of nursing care at the oncology wards is missed. These findings are better than findings which were reported in studies conducted in Ethiopia [12] and Sweden [13] in which the results were about $74 \%$. Whereas, the prevalence of nursing missed care in the current study was higher than the prevalence reported in the New Jersey USA study (10-27\%) [14]. This difference might be due to the study setting and sample size differences.

The present study suggested that provision of oral hygiene to those who need, treatments and some of nursing procedures left undone because of lack of time, and considering cleaning of patients' room and equipment were the most missed care by nurses. These results are in line with studies [13,15]. A study in England reported that most nurses $(86 \%)$ showed that one or more care activity had been left undone due to lack of time on their last shift. Further, Bagnasco, Catania [16] showed that the frequency of omission of

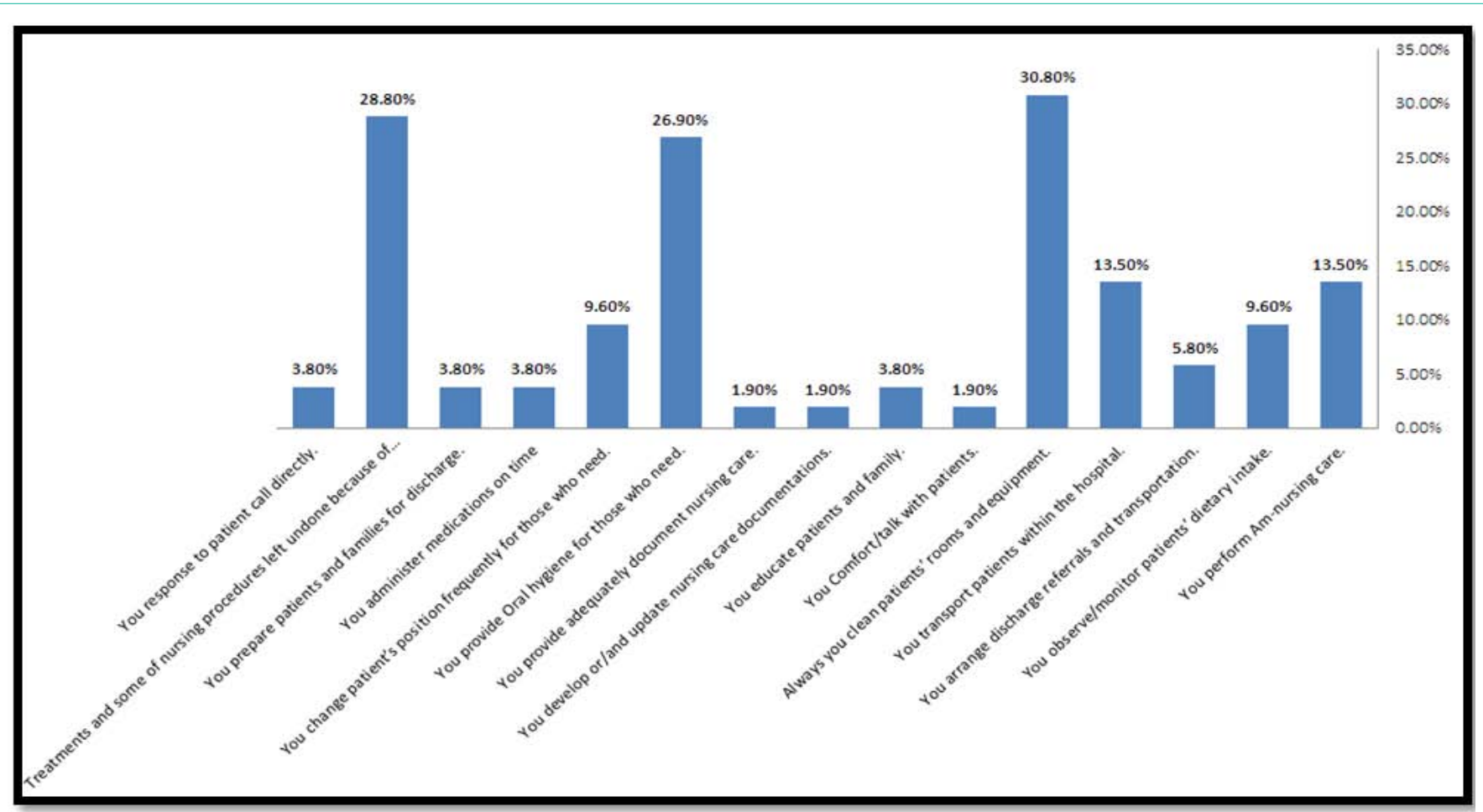

Figure 1: Prevalence of missed care according to those who answered no. 
Table 3: Prevalence of missed nursing care.

\begin{tabular}{|c|c|c|c|c|c|}
\hline Item & Yes n (\%) & Sometimes n (\%) & No $n(\%)$ & Weighted mean (\%) & Rank \\
\hline You perform Am-nursing care & $30(57.7)$ & $15(28.8)$ & $7(13.5)$ & 27 & 5 \\
\hline You observe/monitor patients' dietary intake & $31(59.6)$ & $16(30.8)$ & $5(9.6)$ & 26 & 6 \\
\hline You arrange discharge referrals and transportation & $30(57.7)$ & $19(36.5)$ & $3(5.8)$ & 25.6 & 7 \\
\hline You transport patients within the hospital & $29(55.8)$ & $16(30.8)$ & $7(13.5)$ & 27.3 & 4 \\
\hline Always you consider cleaning of patients' rooms and equipment & $22(42.3)$ & $14(26.9)$ & $16(30.8)$ & 32.6 & 3 \\
\hline You Comfort/talk with patients & $41(78.8)$ & $10(19.2)$ & $1(1.9)$ & 21.3 & 10 \\
\hline You educate patients and family & $40(76.9)$ & $10(19.2)$ & $2(3.8)$ & 22 & 9 \\
\hline You develop or/and update nursing care documentations & $37(71.2)$ & $14(26.9)$ & $1(1.9)$ & 22.6 & 8 \\
\hline You provide adequately document nursing care & $41(78.8)$ & $10(19.2)$ & $1(1.9)$ & 21.3 & 10 \\
\hline You provide Oral hygiene for those who need & $13(25)$ & $25(48.1)$ & $14(26.9)$ & 35 & 1 \\
\hline You change patient's position frequently for those who need & $23(44.2)$ & $24(46.2)$ & $5(9.6)$ & 27.3 & 4 \\
\hline You administer medications on time & $43(82.7)$ & $7(13.5)$ & $2(3.8)$ & 21 & 11 \\
\hline You prepare patients and families for discharge & $38(73.1)$ & $12(23.1)$ & $2(3.8)$ & 22.6 & 8 \\
\hline $\begin{array}{l}\text { Treatments and some of nursing procedures don't left undone because of lack of } \\
\text { time }\end{array}$ & $18(34.6)$ & $19(36.5)$ & $15(28.8)$ & 33.6 & 2 \\
\hline You response to patient call directly & $40(76.9)$ & $10(19.2)$ & $2(3.8)$ & 22 & 9 \\
\hline Overall percentage (\%) & $61 \%$ & $28.40 \%$ & $10.60 \%$ & & \\
\hline
\end{tabular}

Table 4: Nursing missed care associated factors.

\begin{tabular}{|c|c|c|c|c|c|c|c|}
\hline Risk factors & $\begin{array}{c}\text { Strongly } \\
\text { disagree } \mathrm{n}(\%)\end{array}$ & $\begin{array}{l}\text { Disagree } \\
\mathrm{n}(\%)\end{array}$ & $\begin{array}{l}\text { Neutral n } \\
\text { (\%) }\end{array}$ & $\begin{array}{l}\text { Agree } n \\
(\%)\end{array}$ & $\begin{array}{c}\text { Strongly } \\
\text { agree } n(\%)\end{array}$ & $\begin{array}{l}\text { Weighted } \\
\text { mean (\%) }\end{array}$ & Rank \\
\hline $\begin{array}{l}\text { There are adequate support services to allow me to spend time with } \\
\text { my patients }\end{array}$ & $4(7.7)$ & $17(32.7)$ & $11(21.1)$ & $19(36.5)$ & $1(1.9)$ & 32 & 8 \\
\hline Doctors and nurses have good working relationships & $0(0)$ & $4(7.7)$ & $13(25)$ & $33(63.5)$ & $2(3.8)$ & 24.6 & 23 \\
\hline Nursing team has good working relationships & $3(5.8)$ & $7(13.5)$ & $6(11.5)$ & $26(50)$ & $10(19.2)$ & 26.6 & 19 \\
\hline There is a supervisory staff that is supportive of nurses & $3(5.8)$ & $16(30.8)$ & 9 (17.3) & $23(44.2)$ & $1(1.9)$ & 30.6 & 12 \\
\hline $\begin{array}{l}\text { There are active staff development and continuing education programs } \\
\text { for nurses }\end{array}$ & $12(23.1)$ & $10(19.2)$ & $13(25)$ & $14(26.9)$ & $3(5.8)$ & 34 & 7 \\
\hline There is opportunity for career development & $9(17.3)$ & $16(30.8)$ & $10(19.2)$ & $14(26.9)$ & $3(5.8)$ & 34 & 7 \\
\hline $\begin{array}{l}\text { There is opportunity for registered nurses to participate in policy } \\
\text { decisions }\end{array}$ & $14(26.9)$ & $16(30.8)$ & $11(21.2)$ & $9(17.3)$ & $2(3.8)$ & 37.4 & 2 \\
\hline There are clear policy and procedure for all nursing care & $8(15.4)$ & $9(17.3)$ & $13(25)$ & $19(36.5)$ & $3(5.8)$ & 31.2 & 9 \\
\hline Doctors value nurses' observations and judgments & $1(1.9)$ & $8(15.4)$ & $24(46.2)$ & $18(34.6)$ & $1(1.9)$ & 29.2 & 14 \\
\hline $\begin{array}{l}\text { There is enough time and opportunity to discuss patient care with other } \\
\text { nurses }\end{array}$ & $2(3.8)$ & $14(26.9)$ & $18(34.6)$ & $17(32.7)$ & $1(1.9)$ & 31 & 10 \\
\hline $\begin{array}{l}\text { There are enough registered nurses on staff to provide quality patient } \\
\text { care }\end{array}$ & $11(21.2)$ & $22(42.3)$ & $9(17.3)$ & $9(17.3)$ & $1(1.9)$ & 37.8 & 1 \\
\hline There is enough staff to get the work done & $7(13.5)$ & $25(48.1)$ & $9(17.3)$ & $11(21.2)$ & $0(0)$ & 36.8 & 3 \\
\hline Doctors recognize nurses' contributions to patient care & $3(5.8)$ & $10(19.2)$ & $17(32.7)$ & $21(40.4)$ & $1(1.9)$ & 29.8 & 13 \\
\hline I work with nurses who are clinically competent & $1(1.9)$ & $5(9.6)$ & $19(36.5)$ & $21(40.4)$ & $6(11.5)$ & 26 & 20 \\
\hline $\begin{array}{l}\text { I have a nurse manager who backs up the nursing staff in decision } \\
\text { making, even if the conflict is with a doctor }\end{array}$ & $3(5.8)$ & $9(17.3)$ & $14(26.9)$ & $21(40.4)$ & $5(9.6)$ & 28 & 16 \\
\hline Management listens and responds to employee concerns & $7(13.5)$ & $17(32.7)$ & $18(34.6)$ & $8(15.4)$ & $2(3.8)$ & 35 & 5 \\
\hline There is an active quality assurance program & $7(13.5)$ & $20(38.5)$ & $17(32.7)$ & $6(11.5)$ & $2(3.8)$ & 36 & 4 \\
\hline There is a preceptor program for newly hired nurses & $8(15.4)$ & $17(32.7)$ & $13(25)$ & $12(23.1)$ & $2(3.8)$ & 34.6 & 6 \\
\hline There are written, up-to-date care plans for all patients & $4(7.7)$ & $15(28.8)$ & $10(19.2)$ & $22(42.3)$ & $1(1.9)$ & 31 & 10 \\
\hline There are patient care assignments that foster continuity of care & $3(5.8)$ & $6(11.5)$ & $13(25)$ & $26(50)$ & $4(7.7)$ & 26.8 & 18 \\
\hline Staff don't feel like their mistakes are held against them & $6(11.5)$ & $15(28.8)$ & $15(28.8)$ & $13(25)$ & $3(5.8)$ & 29.8 & 13 \\
\hline $\begin{array}{l}\text { Important patient information is often does not loss during shift } \\
\text { changes }\end{array}$ & $2(3.8)$ & $10(19.2)$ & $13(25)$ & $19(36.5)$ & $8(15.4)$ & 27 & 17 \\
\hline $\begin{array}{l}\text { Things don't fall between the cracks when transferring patients from } \\
\text { one unit to another }\end{array}$ & $2(3.8)$ & $18(34.6)$ & $13(25)$ & $14(26.9)$ & $5(9.6)$ & 30.8 & 11 \\
\hline Staff feels free to question the decisions or actions of those in authority & $3(5.8)$ & $9(17.3)$ & $17(32.7)$ & $16(30.8)$ & $7(13.5)$ & 28.2 & 15 \\
\hline
\end{tabular}




\begin{tabular}{|c|c|c|c|c|c|c|c|}
\hline In this unit, we discuss ways to prevent errors from happening again & $3(5.8)$ & $7(13.5)$ & $9(17.3)$ & $21(40.4)$ & $12(23.1)$ & 24.8 & 22 \\
\hline We are given feedback about changes put into place on event reports & $0(0)$ & $9(17.3)$ & $14(26.9)$ & $20(38.5)$ & $9(17.3)$ & 25.4 & 21 \\
\hline $\begin{array}{l}\text { The actions of hospital management show that patient safety is a top } \\
\text { priority }\end{array}$ & $2(3.8)$ & $4(7.7)$ & $10(19.2)$ & $26(50)$ & $10(19.2)$ & 23.6 & 24 \\
\hline Overall percentage (\%) & $9.10 \%$ & $22.70 \%$ & $27.10 \%$ & $34 \%$ & $7.10 \%$ & & \\
\hline
\end{tabular}

nursing activities ranged between $7 \%$ and $50 \%$ and oral care was the most frequently missed care activity.

However, an earlier study in Iran reported that patient discharge planning and teaching, emotional support to patient and/or family, and attend interdisciplinary care conferences whenever held were the missed items by nurses. Moreover, in a cross European study conducted in 12 countries, professional nurses commonly did not 'comfort/talk with patients', had tremendous workloads, lacked autonomy, and their relationships with other healthcare professionals, the support from managers, resources, and incorporation in decision making processes were the main factors leading to interruptions in the preparation for patient discharge [17].

The present study demonstrated that "there are no enough registered nurses on staff to provide quality patient care", "there is no opportunity for registered nurses to participate in policy decisions", "there is no enough staff to get the work done", there is no an active quality assurance program", and "management does not listen and respond to employee concerns" were the most associated factors to the nursing missed care. Many factors for inadequate nursing staff including shortage of staff, increased workload due to high professional experience and required clinical expertise in addition to the high demand for nurses in other sections has been reported [18]. The current study findings were in line with Kalisch, Tschannen [19] which evaluated the association between levels and causes for nursing missed care, and Cho, Kim [20], which compared nursing missed care in Korea with high and low staff and Min, Yoon [21] who investigated the relationship between missed care and nurses' breaks. All of these studies demonstrated that inadequate human resources were the most important factor for the missed nursing care. However, according to Blackman and Willis [22] study, associated factors of missed nursing care included shift type, nursing resource allocation, health professional communication, workload intensity, workload predictability, the nurses' satisfaction with their current job and their intention to remain in their jobs. The differences in results between studies maybe rationalized by the differences between workplace, available human resources, interactions with the nursing team, workload and the total number of cared for patients.

Recently, the shortage of nursing staff due to increased turnover has been recognized as a significant challenge for healthcare systems [23]. A recent systematic review suggested effective policies to reduce the shortage of nurses include new payment arrangements, emergency recruitment, and nurses' residency programs [24]. Furthermore, Managers in the educational and clinical sectors must consider staffing resources and how to initiatives might be developed to support educating qualified candidates. Job descriptions for nurses should be clearly defined. A proper estimation model for staffing in hospitals can support the proper distribution of nursing professionals according to need. Moreover, nurses in developing countries often perform inappropriate activities such as answering phone calls and coordinating patients' appointments with specialists [25]. The distribution and adequacy of medical professionals has been shown to be problematic in developing countries [26]. The Ministry of Health can prioritize the design and embedding of a nursing staff estimation model to support the proper distribution of nurses [27].

The key limitation of the present study is that it was unable to connect nurses' responses to the patients under their care, making it impossible to assess the impact of reported missed care on patient outcomes. This is an essential subject to think about for future research.

\section{Conclusions}

The findings of the current study showed that missed care is common among nurses. The most frequently missed activities reported at the oncology wards in Gaza Strip, Palestine were provision of oral hygiene for those who need, some of nursing procedures and treatments left undone due to lack of time, nurses do not consider cleaning of patients rooms and equipment, and the changing of patients position is not frequently done for those who need. Also, limitation associated with number of nurses and human resources were demonstrated as the most important reason for missing care.

Additionally, the findings of the current study highlighted the need for more quality improvement efforts to reduce missed nursing care in the oncology departments. Considering issues such as shortage in staff number, nurses' continuing education/training programs and involvement in policy decisions, and direct response to the career concerns could reduce the prevalence of missed care.

\section{References}

1. Kalisch BJ, Landstrom GL, Hinshaw AS. Missed nursing care: a concept analysis. Journal of advanced nursing. 2009; 65: 1509-1517.

2. Aycock N, Boyle D. Interventions to manage compassion fatigue in oncology nursing. Clinical journal of oncology nursing. 2014; 13.

3. El Bilbeisi $\mathrm{AHH}$, Albelbeisi A, Hosseini S, Djafarian K. Dietary pattern and their association with level of asthma control among patients with asthma at al-shifa medical complex in Gaza Strip, Palestine. Nutrition and metabolic insights. 2019; 12: 1178638819841394.

4. Warshawsky N, Rayens MK, Stefaniak K, Rahman R. The effect of nurse manager turnover on patient fall and pressure ulcer rates. Journal of Nursing Management. 2013; 21: 725-732.

5. Jones TL, Hamilton P, Murry N. Unfinished nursing care, missed care, and implicitly rationed care: State of the science review. International journal of nursing studies. 2015; 52: 1121-1137.

6. Russell K. The perceptions of burnout, its prevention and its effect on patient care as described by oncology nurses in the hospital setting: Carlow University. 2014.

7. Kalisch B, Tschannen D, Lee $H$. Does missed nursing care predict job satisfaction? Journal of Healthcare Management. 2011; 56: 117-134.

8. Ball JE, Bruyneel L, Aiken LH, Sermeus W, Sloane DM, Rafferty AM, et al. Post-operative mortality, missed care and nurse staffing in nine countries: A cross-sectional study. International journal of nursing studies. 2018; 78 : 
10-15.

9. McHugh MD, Stimpfel AW. Nurse reported quality of care: a measure of hospital quality. Research in nursing \& health. 2012; 35: 566-575.

10. El Bilbeisi A, El Afifi A, Baloushah S, Alblbeisi A, Albelbeisi A, Taleb MJAJNFS. Maternal Dietary Patterns during Early Pregnancy and Their Association with Pregnancy Outcome among Obese Women in Gaza Strip, Palestine: a Prospective Cohort Study. Austin J Nutri Food Sci. 2020; 8: 1138.

11. Roche MA, Duffield C, Friedman S, Twigg D, Dimitrelis S, Rowbotham S Changes to nurses' practice environment over time. Journal of nursing management. 2016; 24: 666-675.

12. Haftu M, Girmay A, Gebremeskel M, Aregawi G, Gebregziabher D, Robles C Commonly missed nursing cares in the obstetrics and gynecologic wards of Tigray general hospitals; Northern Ethiopia. PloS one. 2019; 14: e0225814.

13. Ball JE, Murrells T, Rafferty AM, Morrow E, Griffiths P. 'Care left undone'during nursing shifts: associations with workload and perceived quality of care. BMJ quality \& safety. 2014; 23: 116-125.

14. Hessels AJ, Flynn L, Cimiotti JP, Cadmus E, Gershon RR. The impact of the nursing practice environment on missed nursing care. Clinical nursing studies. $2015 ; 3: 60$.

15. White EM, Aiken LH, McHugh MD. Registered nurse burnout, job dissatisfaction, and missed care in nursing homes. Journal of the American Geriatrics Society. 2019; 67: 2065-2071.

16. Bagnasco A, Catania G, Zanini M, Dasso N, Rossi S, Aleo G, et al. Are data on missed nursing care useful for nursing leaders? The RN4CAST@ IT cross-sectional study. Journal of Nursing Management. 2020; 28: 2136-2145.

17. Chegini Z, Jafari-Koshki T, Kheiri M, Behforoz A, Aliyari S, Mitra U, et al. Missed nursing care and related factors in Iranian hospitals: A cross-sectional survey. Journal of nursing management. 2020; 28: 2205-2215.

18. Khademi M, Mohammadi E, Vanaki Z. Resources-tasks imbalance: Experiences of nurses from factors influencing workload to increase. Iranian journal of nursing and midwifery research. 2015; 20: 476
19. Kalisch BJ, Tschannen D, Lee KH. Do staffing levels predict missed nursing care? International Journal for Quality in Health Care. 2011; 23: 302-308.

20. Cho SH, Kim YS, Yeon K, You SJ, Lee I. Effects of increasing nurse staffing on missed nursing care. International nursing review. 2015; 62: 267-274.

21. Min A, Yoon YS, Hong HC, Kim YM. Association between nurses' breaks, missed nursing care and patient safety in Korean hospitals. Journal of nursing management. 2020; 28: 2266-2274.

22. Blackman I, Willis E. A study exploring the effectiveness of the MISSCARE tool in determining the frequency, type and reasons for missed nursing care: a psychometric evaluation'. Journal of Nursing Measurement. 2014; 22: 421 437.

23. Chegini Z, Asghari Jafarabadi M, Kakemam E. Occupational stress, quality of working life and turnover intention amongst nurses. Nursing in critical care. 2019; 24: 283-289.

24. Park H, Yu S. Effective policies for eliminating nursing workforce shortages: a systematic review. Health Policy and Technology. 2019; 8: 296-303.

25. Adib-Hajbaghery $M$, Zare $M$. The barriers to patient education from the viewpoint of nurses in iran: a systematic review. Nursing and Midwifery Journal. 2017; 15: 544-558.

26. Nobakht S, Shirdel A, Molavi-Taleghani Y, Doustmohammadi MM, Sheikhbardsiri $\mathrm{H}$. Human resources for health: A narrative review of adequacy and distribution of clinical and nonclinical human resources in hospitals of Iran. The International journal of health planning and management. 2018; 33: $560-572$

27. Tabatabaee SS, Vafaee-Najar A, Amiresmaili MR, Nekoie-Moghadam M. Nurse staffing norm in Iran Hospitals: What features should be included for success? International Journal of Preventive Medicine. 2017; 8. 